\title{
Anaerobic digestion concert of agro-food wastes and the correlated microbial population dynamics under suboptimal, well-performed and disturbed states
}

\author{
Dong-min Yin ${ }^{1}$, Dr. Ahmed Mahdy ${ }^{2}$, Yue-ling Liu ${ }^{1}$, Camilla Negri ${ }^{3}$, Davide Bianchi ${ }^{3}$, \\ Fabrizio Adani ${ }^{4}$, Wei qiao ${ }^{1}$, and Renjie Dong ${ }^{1}$ \\ ${ }^{1}$ China Agricultural University \\ ${ }^{2}$ Zagazig University \\ ${ }^{3}$ University of Milan \\ ${ }^{4}$ Universita degli Studi di Milano
}

May 5, 2020

\begin{abstract}
The comparison among microbial interactions during the stable performance of anaerobic digestion (AD) and the process disturbances is still lack and could limit the prediction of process failure and the possible recovery. This study aimed at characterizing the process performance and microbial communities' profiles during the stable and disturbed states of long-term thermophilic AD process fed with agro-food wastes. The disturbances were induced in two stages, firstly under a stepwise increase of organic loading rate (OLR), and then through the reduction in hydraulic retention time (HRT). Volatile fatty acids (VFAs) only accumulated (4730 mg L-1) when OLR increased to $17 \mathrm{~g}$ VS L-1 d-1, and consequently methane yield deteriorated by $47 \%$, implying process overloading and thus AD process was partially inhibited. Process disturbances led to $30 \%$ reduction in relative abundance of Defluviitoga and Methanoculleus which were partially displaced by Clostridium and Methanomassiliicoccus, implying that the process acidification immediately reflected on microbial profile and the microbes were functionally redundant. Microorganisms' washout was the main reason behind methane yield drop under finite digestion time (1.5d). Microbial profiles shaping showed the robustness of AD process due to the functionally redundant microorganisms and could be strategically used to control and optimize AD process.
\end{abstract}

\section{Introduction}

Since the time of the industrial revolution, the utilization of fossil fuels has severe environmental pollution which was the direct cause of global warming (GW) because of the emission of greenhouse gases (GHG). Therefore, the 'road map' indicates that by 2050, according to internal energy agencies (REN21 report, 2013), about $75 \%$ of the global primary energy supply ought to be renewable. Agro-food wastes provide huge amounts of biodegradable materials which can be recycling to recover energy or commercial products as bio-refinery processes. In china alone, for example, the annual production of food waste and crop straw are about 30 and 600 million tons, respectively (Chen et al., 2012; Dongyan et al., 2014). Numerous negative environmental aspects, such as aquatic life toxicity, altered soil quality, phyto-toxicity, GHG and mal odor may be emerged because of improper practices of such wastes (Nayak and Bhushan 2019). As a consequence, it is crucial to develop a specific, efficient and sustainable approach for treatment of agro-food wastes.

Anaerobic digestion, a microbial-based process where the microorganisms play a pivotal role in degrading organic pollutants to biogas, is one of the most efficient waste management strategies worldwide and thus 
"two-in-one" advantage of waste disposal and energy production could be achieved. AD is divided to four interdepended processes namely, hydrolysis, acidogenesis, acetogenesis and methanogenesis where the products of one stage are the substrate of the other stage until the biogas is produced. The syntrophic relationship among the microorganisms (bacteria and archaea) involved in these stages is the key for the process stability.

Mechanisms of microbial assemblage in anaerobic digestion process remain unclear. However, temperature, substrate composition, OLR and HRT represented most important operating conditions, affecting structure of anaerobic microbiome (Cho et al., 2017; Nag et al., 2019). The disturbances in such parameters were reported to play a crucial role in the microbial profiles shaping as a result of accumulation of some intermediate products such as VFAs. The methanogens, for instance, are the most sensitive to process disturbances and thus result in unbalance between VFAs producers and consumers. As a matter of fact, there are three basic behaviors could be distinguished in the microbial dynamics under harsh conditions, namely, 1) resistance in which microbes can deal with changes and thus no composition variation will take place, 2) resilience in which microorganisms able to recover after upset and 3) redundant in which new microbes have the ability to replace the disturbed populations (Carballa et al., 2015). Even though microorganisms involved in different AD stages are functionally redundant (De Vrieze et al., 2017; Zhang et al., 2019), the distinct members that are able to replace each other upon operational disturbances need more investigation.

Since operational disturbances such as temperature fluctuation or over feeding may accidently occur during the industrial-scale operation. Therefore, it is essential to clarify the effect of the disturbances in process performance and link it to microbial population. Indeed, the impacts of operating parameters disturbances on process stability were frequently investigated with regard to their effects on biodegradability efficiency and biogas production (Mahdy et al., 2015). A sharp drop in methane yield and high VFAs concentration $(9000 \mathrm{mg} / \mathrm{L})$ were observed when OLR increased up to $6 \mathrm{~g} \mathrm{VS} / \mathrm{L} / \mathrm{d}$ (Li et al., 2015). However, kinetics synergies among interdependent reactions and its correlating to microbial dynamic and function under stable and harsh conditions still so far unclear and require more investigation. Some investigations have revealed microbial community composition in many healthy anaerobic digesters to enhance the process management (Li et al., 2016; Li et al., 2019). Other studies have even linked harsh conditions (extreme ammonia, HRT, temperature and OLR disturbances) with microbial profiles in healthy AD process. For instance, Tian et al., (2018) studied population dynamics in digesters with step-wise increase in ammonia concentration up to $10 \mathrm{~g} \mathrm{NH} 4 / \mathrm{L}$ with stable methane production (more than 95\% on uninhibited phase). Jiang et al. (2019) revealed the stability of process performance and microbial structure under ambient temperature. Mahdy et al., (2019a) demonstrated microbial community shifts in the digesters with different OLRs and HRT under stable-state conditions. A very few studies have taken the deteriorative phase into accounts. Furthermore, although it is well accepted that high loading rate with short retention time, for instance, could increase the process capacity of the plant, the processes under such conditions have to be handled carefully and the entire process management including the response of the $\mathrm{AD}$ microbiome should be fully assumed.

Therefore, this study aimed to compare the process performance and the population profiles that were stablished at optimal OLR and HRT in AD process fed with agro-food wastes with that attained under organic overloading and finite digestion time. To achieve this goal, 5 different OLRs were investigated and meanwhile HRTs were shortenings down to 1.5 day, during which methane yield, methane production and major intermediates were evaluated as well as phylogenic analyses targeting $16 \mathrm{~S}$ rRNA sequences and quantitative polymerase chain reaction (qPCR) were performed to monitor microbial communities of each state. Overall, the objective of this study was the highlighting attempt to reveal how processes respond to varying exterior effects and how the performance of $\mathrm{AD}$ microorganism can be reacted and thus the comparison between well-performed and disturbed microorganism could be used for knowledge-based process control.

\section{Materials and methods}

\subsection{Summarize of raw materials and inoculum}

Food waste was sampled from the students' canteen during lunchtime in China Agricultural University every 
2-3 weeks. Unsuitable materials, including bones, plastic, and chopsticks etc, were picked out by hand in laboratory and then the food waste was shattered with a blender (Joyoung JYLC012, China) for 5 minutes and stored in plastic bottles at $4^{\circ} \mathrm{C}$. Maize straw was crushed by a small grinder (HC-1000Y2, China), sieved using a $40 \mathrm{~mm}$ sieve and stored. The inoculum was initially collected from an operated anaerobic plant with feedstock of cornstalk under thermophilic condition. The basic characteristics of food waste, maize straw and inoculum are shown in Table (1).

\subsection{Experimental design and operation}

A continuous stirred tank reactor (CSTR) was setup with a whole volume of $2.5 \mathrm{~L}$ (2 L of working volume) under thermophilic conditions $\left(55 \pm 1^{\circ} \mathrm{C}\right)$. The reactor was stirred automatically every $2 \mathrm{~h}$ for $10 \mathrm{~min}$ at a speed of 50-90 rpm and a thermostatic circulating water tank (HH-60, China) was employed to keep the set-up temperature. The reactor was fed with a mix of straw and food waste (1:1 on dry matter basis) for 270d in two stages. During the first stage (1-218 days), the reactor was operated by a stepwise OLR-increase program, i.e. from 2.6 to 5.4, 7.9, 10.2 and $17.1 \mathrm{~g}$ VS L-1 d-1. A peristaltic pump (BT300N-YZ1515x, China) was applied for 4 times feeding per day and controlled by a timer and a relay. The process upset in the first stage was temporary and was resolved by stop feeding until the accumulated VFAs from the previous period were depredated (from 219-230 day). During the recovery period, the accumulated VFAs reduced from 3725 down to $295 \mathrm{mg}$ L-1. Once process stability was restored by day 230 of operation, the second stage (231-270 days) was designed with a stepwise HRT decrease from 5 to 3 and finally to 1.5 with the best OLR obtained in first stage (Table 2). The feedstock was fed into into the reactor 6 times per day by the timer and a peristaltic pump. The daily effluent of the reactor was withdrawn before the influent addition by a peristaltic pump.

\subsection{Chemical analyses}

Effluent samples were taken from the reactor every 1-3 days under different stages. The total solids (TS), volatile solids (VS) of the substrates and effluent were measured with dry methods to a constant weight at $105^{\circ} \mathrm{C}$ for $24 \mathrm{~h}$ in an electric heating air-blowing drier and at $600^{\circ} \mathrm{C}$ for $2 \mathrm{~h}$ in a muffle stove, respectively (Sluiter et al., 2005). Total and soluble chemical oxygen demand (TCOD and SCOD), and ammonium nitrogen were sampled every three days, and then measured with standard methods (APHA 2005). Contents of $\mathrm{C}, \mathrm{H}, \mathrm{O}, \mathrm{N}, \mathrm{S}$ were measured through a Macro Element Analyzer. The biogas (CH4 and CO2) composition, volume, VFAs and $\mathrm{pH}$ were determined as previously described (Mahdy et al., 2019b). One-way analysis of variance (ANOVA, $p<0.05)$ was applied to identify the statistical significance.

\subsection{S rRNA sequences}

Samples were collected directly from anaerobic digester within steady-state conditions (the 200th and 213th days) for microbial community analyses at OLR of 10.2 and $17.1 \mathrm{~g}$ VS L-1 d-1, respectively (first stage). In addition, the microbial samples were also obtained during the shortening of the HRT from 5 to 1.5d (second stage) after 3 HRTs during process stability. Samples were stored at $-20^{\circ} \mathrm{C}$ until being analysed. DNA extraction, 16S rRNA amplification, PCR procedures and sequencing libraries were operated according to previous studies (Yin et al, 2018). Representative sequences were filtered for each operational taxonomic unit (OUT). Three alpha diversity i.e. Chao1 (microbial richness), Shannon and Simpson (microbial diversity) were calculated with rarified OTU table.

Total bacteria and three abundant methanogen orders, Methanobacteriales, Methanosarcinales and Methanomicrobiales, were detected by using Quantitative polymerase chain reaction (qPCR) to analyze the microbial community dynamics when shortening the HRT from 5 to $1.5 \mathrm{~d}$. Primers were designed according to the $16 \mathrm{~s}$ rRNA gene sequence as a previous study (Shi et al., 2018). Slurry sample at HRT of 5d was amplified by PCR using four sets of primers. The fragments were recovered from the gel, ligated to the PUC-T vector, and then transformed into E. coliDH5a for cultivation. Positive clones were selected to extract plasmids, and nucleic acid detectors were used to determine the concentration and purity. The concentrations were converted to copies and serially diluted. The purified PCR products were then sequenced, and verified. Real Time PCR system (EDC-810, China) was performed as qPCR. A qPCR mixture $(20 \mu \mathrm{L})$ containing $1 \mu \mathrm{L}$ of 


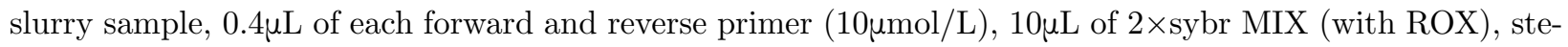
rile water to a total of $20 \mu \mathrm{L}$, and Power SYBR Green (Baygene BG-Power600, China) were used to prepare template DNA (20ng). The amplification processes of the total bacteria and the order Methanobacteriales were as follows: A cycle consisted of $3 \mathrm{~min}$ at $94^{\circ} \mathrm{C} ; 94^{\circ} \mathrm{C}$ for $15 \mathrm{~s}$ with totally 40 cycles, $20 \mathrm{~s}$ at $60^{\circ} \mathrm{C}, 72^{\circ} \mathrm{C}$ for $20 \mathrm{~s}, 2 \mathrm{~min}$ at $72^{\circ} \mathrm{C}$; and extension at $72^{\circ} \mathrm{C}$ for $20 \mathrm{~s}$. The additional steps for the orders Methanosarcinales and Methanomicrobiales were carried out at $94^{\circ} \mathrm{C}$ for $15 \mathrm{~s}$ with 40 cycles, i.e. $52^{\circ} \mathrm{C}, 72^{\circ} \mathrm{C}$ and $72^{\circ} \mathrm{C}$ for $20 \mathrm{~s} 30 \mathrm{~s}$ and $2 \mathrm{~min}$, respectively; and extension at $20 \mathrm{~s}$ at $72^{\circ} \mathrm{C}$. For each primer and probe set, a control without the equivalent template DNA was consisted in every qPCR assay. Triplicate standard samples were constructed for each primer set, of which one was selected to draw a standard curve.

\section{Results and discussion}

The data presented in Table 1 demonstrates the characteristics of food wastes and maize straw before being mixed to be used as substrate for anaerobic digestion process. The predominant macromolecule of food wastes was lipid, exhibited $37.4 \%$ of total macromolecules. The protein fraction was approximately $21 \%$ of total macromolecules. Both macromolecules summed up $60 \%$ of total food wastes macromolecules, mediating $\mathrm{C} / \mathrm{N}$ ration to be relatively low (14). Opposite, the prevailing content of $\mathrm{C}$-rich molecules in maize straw mediated a higher $\mathrm{C} / \mathrm{N}$ ratio to be 53 , which acts as a limiting factor for the regular growth of bacteria. Macromolecules distribution and elemental analyses attained for food wastes and maize straw is in good agreement with literature (Algapani et al., 2016; Peng et al., 2016). The characteristic results of both substrates indicated that both substrates were far away of ideal $\mathrm{C} / \mathrm{N}$ ratio for anaerobic digestion i.e. 20 to 30 (Nayak and Bhushan 2019) and this ratio thus needs to be adjusted. In this study, the mixture of N-rich food waste and C-rich maize straw by (1:1) had a balanced $\mathrm{C} / \mathrm{N}$ ratio of 33 .

\subsection{Process performance under stable and disturbed states targeting OLR}

As shown in Fig. 1a, in the first stage, when the OLR was promoted from 2.6 to 5.4, 7.9 and $10.2 \mathrm{~g}$ VS L-1 $\mathrm{d}-1$, the biogas production gradually increased from 0.9 to 3.0, 4.6, and 5.7 L L-1 d-1, respectively. However, an additional increase in OLR (17.1 g VS L-1 d-1) resulted in a sharp decrease in the biogas production. The highest specific methane yield measured under a steady-state was $393 \pm 25 \mathrm{~mL}-\mathrm{CH} 4 \mathrm{~g}$ VSin- 1 at $7.9 \mathrm{~g}$ VS L-1 d-1 of OLR. No-significant $(p>0.05)$ reduction was observed with the OLR promoted to $10.2 \mathrm{~g}$ VS L-1 d-1 (i.e. $385 \pm 25 \mathrm{~mL}$ g VSin). Contrary, the specific methane yield significantly $(p<0.05)$ decreased down to $348 \pm 59 \mathrm{~mL} \mathrm{~g}$ VSin at $5.4 \mathrm{~g}$ VS L-1 d-1. Results reported in previous studies were less than that attained in current study in both the thermophilic and mesophilic AD processes of agro-food wastes (Hobbs et al., 2019; Shi et al., 2018) which may be more likely related to the $\mathrm{C} / \mathrm{N}$ balance and/or a good synergistic of such substrates. Remarkably, the specific methane yield dropped suddenly at $17.1 \mathrm{~g}$ VS L-1 d-1 of OLR (Fig. 1b), implying process overloading and thus AD process was partially inhibited. These results indicated that the capacity of the process could be increased with increasing OLR up to $10 \mathrm{~g}$ VS L- 1 d- 1 without affecting the process stability, however a closer look into common intermediates could be helpful to elucidate the reason behind the observed methane yield reduction at highest OLR.

In Fig. 1c, the total VFAs content in the reactor varied between 124-398 mg L-1 under different OLRs up to $10.2 \mathrm{~g}$ VS L-1 d-1. All VFAs values were much lower than $1000 \mathrm{mg} \mathrm{L}-1$, the threshold reported as the levels in which acid suppression becomes evident (Chen et al., 2012), implying that the activity of anaerobic microbiome (acidogens, acetogens and methanogens) was balanced and consequently, proper operation concert was achieved. Nevertheless, the OLR of 2.6 and $5.4 \mathrm{~g}$ VS L-1 d-1 were not enough for an efficient performance and thus their methane yields were lower than higher OLR. On contrary, once the OLR reached $17.1 \mathrm{~g}$ VS L-1 d-1, the VFAs accumulated sharply to $4730 \mathrm{mg}$ L-1 which triggered the cessation of the methane production (Table 2 and Fig. 1). It seems likely that additional increase in OLR over than $10.2 \mathrm{~g}$ VS L-1 d-1 led to organic matters overload and accordingly, unbalance equilibrium between acidogenesis/acetogenesis and methanogenesis took place. These results signified that different microbial groups might be influenced differently at variable OLRs. The acetate is the main driver for the overall methane production, nevertheless, the accumulation of acetate $(1,411 \mathrm{mg} \mathrm{L}-1$ in this study with an OLR of $17.1 \mathrm{~g}$ VS L-1 d-1) could hamper not only acetogenic bacteria but also the degradation of propionate 
(Wagner et al., 2014). By this way, the propionate/acetate ration could serve as a reliable indicator for bacteria stress in overloaded digesters and impending failure (Marchaim and Krause 1993). In this study, the VFA composition for AD carried out at OLR of $17.1 \mathrm{~g}$ VS L- $1 \mathrm{~d}-1$ was quite different compared to the steady-state period (OLR[?]10.2 g VS L-1 d-1) during which acetic and propionic acid were at an average concentration of lower than 340 and $50 \mathrm{mg} \mathrm{L}-1$, respectively. In fact, propionate (2213 $\mathrm{mg} \mathrm{L}-1)$ tended to dominate the VFAs (accumulated to $4730 \mathrm{mg} \mathrm{L}-1$ ) at OLR of $17.1 \mathrm{~g}$ VS L-1 d-1 (Fig. 1c), implying a lower substrate utilization by acetogens. The fluctuation in the VFA content was in accordance with the specific methane yield (Fig 1b, c), indicating a close relationship between VFAs concentration and methane yield and consequently, an overloading of the system and subsequent reduction in methane production were attained.

Interestingly, despite the main reason of inhibition associated with VFAs being the creation of a $\mathrm{pH}$ decline, the $\mathrm{pH}$ values (Fig. 1b) registered under acceptable levels for AD process regardless OLR levels. The $\mathrm{pH}$ values for all OLRs were between 7.2 and 7.6 throughout the first stage of the experiment (OLR 2.6-17.1 g VS L-1 d-1). The volatile solids removal calculated under different OLRs was $60 \%+-7 \%$ except at 17.1 VS L-1 d-1 of OLR (continuously decreasing) (Fig. 1d). Specifically, VS removal efficiency with OLR of $17 \mathrm{~g}$ VS L-1 d-1 decreased 2-fold when the value was compared to data attained with other OLRs. These values are in good agreement with the values attained for methane yields which were sharply declined, leading the process to be crashed. The data was in agreement with previous investigation that OLR is a deterministic parameter affecting the process performance by shaping the microbial profile in the digesters (Mahdy et al., 2019a). Consequently, both OLR of 7.9 and 10.2 g VS L-1 d-1 which demonstrated highest methane yields with stable performance could be considered as optimal ORL threshold when treating agro-food wastes and thus both values are recommended for process optimization.

\subsection{Microbial communities under well-performed and disturbed states targeting OLR}

Linking the microbial dynamics to process perturbations is fundamental in order to understand and deal with process instability. Therefore, two OLRs were chosen in order to investigate the microbial community structure, i.e. during process stability at $10.2 \mathrm{~g}$ VS L-1 d-1, and subsequent process disturbances $(17 \mathrm{~g}$ VS L-1 d-1). In Fig. 2, bacterial community compositions slightly changed under the two OLR conditions although the abundances were different.Thermotogae (phyla Thermotogae) were the predominant bacterial class, followed by Clostridia (phyla Firmicutes ) and Synergistia (phyla Synergistetes) at both OLRs. It has been reported that a significant number of members belonging to phylum Thermotogae frequently seem to be higher in thermophilic digesters (Shi et al., 2018). This phenomenon may be attributed to their ability to encode thermo-stable enzymes that play a role in conversion processes (Conners et al., 2006). At an OLR of $10.2 \mathrm{~g}$ VS L-1 d-1, Defluviitoga (79.7\%) dominated the microbial genera (Fig. 2a). At an OLR of $17.1 \mathrm{~g}$ VS L$1 \mathrm{~d}-1$, Defluviitoga decreased to $49.8 \%$ but there were significant increases in Clostridium and Anaerobaculum (Fig. 2b), implying that these microorganisms were functionally redundant. Accordingly, it was obvious that the increase in OLR resulted in alternation of the microbial abundant during the experiment. Furthermore, the decline in relative abundance ofDefluviitoga was associated with process failure, signifying its significant role in substrate metabolism and process stability.Defluviitoga spp. are able to utilize a wide range of carbohydrate as electron donors (Hania et al., 2012), thus the C-rich straw in the substrate mixture might promote the enrichment of this genus. Defluviitoga spp. frequently exists not only in thermophilic AD (Hania et al., 2012), but also in metabolic association with hydrogenotrophic methanogens (Maus et al., 2016).

In this study, genera Tepidanaerobacter, Clostridium andSyntrophaceticus, which were three possible syntrophic acetate oxidation bacteria (SAOB), were detected at an OLR of 10.2 and $17.1 \mathrm{~g}$ VS L-1 d-1. As depicted in Table 3,Clostridium sp. represented $2.8 \%$ and $11 \%$ of total bacterial at 10.2 and $17.1 \mathrm{~g}$ VS-1 L-1 d-1 of OLR, respectively. Consequently, the reduction in the relative abundance of most dominant carbohydrate-fermenting species (Defluviitoga) might be linked to simultaneous increase in relative abundance of Clostridium sp. and meanwhile promoted carbohydrate availability in digester. The increased presence of SAOB indicated the existence of SAOB combined with a hydrogenotrophic methanogenesis (HM) pathway for methane formation. SAOB of generaTepidanaerobacter and Syntrophaceticus were also 
detected even though they were at less than $0.5 \%$ during the two OLRs.Syntrophomonas, which is known to function as a syntrophic microbe to degrade complex organic matters to simple fatty acids (Hansen et al., 1999), was detected with little change in its relative abundance with the OLRs of 10.2 and $17.1 \mathrm{~g}$ VS L-1 d-1 (0.7\% and $1 \%$, respectively).

Hydrogenotrophic methanogens (including the genera Methanoculleusand Methanothermobacter) represented $88.2 \%$ and $53.5 \%$ of all archaea population for OLRs of 10.2 and $17.1 \mathrm{~g}$ VS L-1d-1, respectively (Fig. 2c, and 2d). The genus Methanoculleus clearly dominated at OLR of $10.2 \mathrm{~g}$ VS L-1d-1 (86.9\%) and OLR of $17.1 \mathrm{~g}$ VS L-1d-1 (52.8\%). Methanoculleus has been reported to be a very efficient hydrogen-utilizing methanogen during the thermophilic AD of chicken manure (Bayrakdar et al., 2017) and it acts as an important partner with Clostridium ultunenes (Yin et al., 2018). The increased OLR to $17.1 \mathrm{~g}$ VS L-1d-1, as previously stated, reduced the presence of Methanoculleus, and coincided with the VFA accumulation and the reduction of methane production (Fig. 1a and 1c). Methylotrophic Methanomassiliicoccuswere represented at relatively low levels at the two OLRs, however, their relative abundance was obviously enhanced at highest OLR. Methanomassiliicoccus is a H2-dependent methanogen which can consume methylated compounds to produce methane (Liu et al., 2016). Nevertheless, it has still not been identified to act as a hydrogenotrophic partner for SAO and it needs to be further verified (Westerholm et al., 2016). In fact, the important role of both Methanoculleus and Methanomassiliicoccus have been previously reported in AD of lignocellulosic biomass ( $\mathrm{Li}$ et al., 2018a). The acetoclastic methanogens, Methanosarcina accounted for only $2 \%$ and $4 \%$ of the total archaea at an OLR of 10.2 and $17.1 \mathrm{~g}$ VS L-1d-1, respectively (Fig. 2). In this study, the high abundance of hydrogenotrophic methanogens, and a low representation of acetoclastic methanogens at OLR of $10.2 \mathrm{~g}$ VS L-1d-1, alongside a low concentration of acetate (338 mg L-1), strongly indicated that the acetate conversion may be a two-stage process.

\subsection{Process performance under stable and disturbed states targeting HRT}

During the HRT shortening stage (Fig. 3), the volumetric biogas production registered was stable at around $4.4 \mathrm{~L} \mathrm{~L}-1 \mathrm{~d}-1$ under $5 \mathrm{~d}$ HRT (Fig. 3a). The specific methane yield was $354+-27 \mathrm{~mL} \mathrm{CH} 4 \mathrm{~g}-1 \mathrm{VS}-1$, and it represented the $65 \% \mathrm{v} / \mathrm{v}$ of the biogas (Table 2). This result fell within the range reported, i.e. 182-368 $\mathrm{mL}$ CH4 g-1 VS-1, in previous studies treating straw and food waste in batch reactors (Liu et al., 2018); however, it was higher than that reported for the mono digestion of food waste at longer HRT under thermophilic conditions (Kim et al., 2006), implying a synergistic effect of the co-digestion strategy. The methane yields declined by $29 \%$ (251+-63 mL CH4 g VSin-1) alongside with the decrease of the HRT to 3 and by $78 \%$ (78+-12 mL CH4 g VSin-1) with HRT shortened to $1.5 \mathrm{~d}$, respectively.

With the decrease in the HRT, the propionate concentration only slightly changed while the acetate concentration accumulated from 333+-197 mg L-1 to $951+-577$ and $2533+-496 \mathrm{mg} \mathrm{L}-1$ at HRT of 5,3 and 1.5 d, respectively (Fig. 3c and Table 1). The concentration of propionate at HRT of $1.5 \mathrm{~d}$ was stable at about 224+-75mg L-1 and so it was 2-fold lower than that reported in HRT of 5d. It was therefore obvious that the consumption rate of acetate was the primary rate-limiting factor at HRTs of 3 and $1.5 \mathrm{~d}$. Although the concentration of VFAs sharply increased during the shortest HRTs, it was much lower than VFAs concentration at OLR of $17.1 \mathrm{~g}-1$ VS L- $1 \mathrm{~d}-1$ in the first stage of current study. Therefore, the reason behind the reduction in gas production rate at this stage was most probably due to the excessive microbial washout caused by the shortest HRTs, and partially because of the impact of VFA accumulation on methanogens activity. The phenomena of the washout effects and the inhibition of VFA have been previously reported under HRT shortened to 5d (Algapani et al., 2016).

The VS removal efficiency with the shortening of the HRT was consistent with the methane production results and this further verified the VFA accumulation. Alongside with the decrease of the HRT, the removal efficiency of VS decreased down to $5.2 \%$ at the end of experiment, which was 11-fold less than the removal efficiency attained at an 8d HRT. The variation of $\mathrm{pH}$ between different HRTs was negligible and varied between 7.2 and 7.3. To conclude, the low methane production during the shortest HRT can be explained by i) the finite digesting time; ii) the microbiome washout effect; and iii) methanogenesis inhibition by VFA accumulation. 


\subsection{The washout of microbial communities at a very short HRT}

In Table 4, the microbial (bacteria and archaea) richness and diversity were obviously higher at a 5d-HRT and this gradually decreased with HRT shortening. To be specific, OTUs of Chao1 estimations decreased by $26 \%$ and $33 \%$ in bacteria and $23 \%$ and $29 \%$ in archaea when accompanied by a decrease in the HRT from 5 to 3 and 1.5d, respectively. The same trend was observed with Shannon and Simpson values although the reduction of archaea diversity was greater than bacteria. However, all richness and diversity scores observed in this study during the shortest HRT (1.5d) were quite similar to data observed with different substrate (cow manure) at a longer HRT ( $25 \mathrm{~d}$ ) while bacteria richness in the current study was obviously higher (Sun et al., 2015).

qPCR was performed during the reducing of HRTs. Genes of total bacteria sharply decreased from 2.17x106 copies $\mu \mathrm{L}-1$ at HRT of $5 \mathrm{~d}$ down to $1.55 \times 104$ copies $\mu \mathrm{L}-1$ at HRT of $1.5 \mathrm{~d}$. This data was much lower than that previously reported for an AD process dealing with food waste at HRT of 20d and OLR of $8.21 \mathrm{~g}$-COD.L-1, i.e. $1.2 \times 107$ copies $\mu \mathrm{L}-1$ (Jang et al., 2016). The trend of the three most abundant archaeal populations during the HRT decreasing showed a pattern close to that of the bacterial/archaeal ratio (Fig. 4), i.e. for HRT of 5,3 and $1.5 \mathrm{~d}$, the total archaeal population sharply decreased from $3.47 \times 105$ to $3.4 \times 104$ and then to $0.9 \times 104$ copies $\mu \mathrm{L}-1$. Correspondingly, the bacterial/archaeal ratio showed its steepest decline when the HRT dropped from 3d to $1.5 \mathrm{~d}$, accompanied by the decline of the methane yield from 223 to $51 \mathrm{~mL}-1 \mathrm{~g}-1$ VS. This indicated that the methanogenic population had declined significantly and was unable to support a remarkable methane production at HRT between $3 \mathrm{~d}$ to $1.5 \mathrm{~d}$. Moreover, the significant decrease of VS removal efficiency occurred (from $39.4 \%$ to $5.2 \%$, Fig. 3d) together with the accumulation of the VFA level (Fig. 3c). This thus indicated that HRT of $1.5 \mathrm{~d}$ was too short and led to a fast-microbial washout which reduced the process performance (Table 2). Three major methanogenic orders at HRTs of 5,3 and 1.5 $\mathrm{d}$ were also quantified. The order Methanobacteriales significantly decreased from $4.76 \times 104$ to $0.84 \times 104$ copies $\mu \mathrm{L}-1$ when passing from HRT of $5 \mathrm{~d}$ to $1.5 \mathrm{~d}$. OrdersMethanosarcinales and Methanemicrobiales were $2.49 \times 104$ and $2.75 \times 105$ copies $\mu \mathrm{L}-1$ at $3 \mathrm{~d}$ HRT, and both decreased to $0.05 \times 104$ copies $\mu \mathrm{L}-1$ when the HRT was shortened to $1.5 \mathrm{~d}$ (Fig. 4). The results indicated that a very short HRT cannot sustain the thermophilic $\mathrm{AD}$ operation although the thermophilic bacterial had a faster growth rate.

\subsection{Microbial community under suboptimal and disturbed states targeting HRT}

In the second stage (231-270 days), the bacterial genera were mainly consisted of $S 1$ (Thermotogae phyla),Cellulosibacter (Firmicutes phyla) and Clostridium(Firmicutes phyla) (Fig.5 a-c). These results corresponded with those reported previously in similar substrates, i.e. food waste and/or rain tree leaf with a longer HRT (20 days) (Ratanatamskul and Manpetch 2016; Zamanzadeh et al., 2017). It was previously shown that the genus $S 1$ was probably $\mathrm{SAOB}$ ( $\mathrm{Li}$ et al., 2018b) but it has not yet been identified. In the present study, possible SAOB (genera Tepidanaerobacter and Clostridium ) (Tachaapaikoon et al., 2012) were detected at HRTs of 5, 3, and 1.5 day (Table 3). The total percentage of potential SAOB increased from $6 \%$ to $11 \%$ as the HRT was shortened from $5 \mathrm{~d}$ to $1.5 \mathrm{~d}$. The abundance of genus Tepidanaerobacter was $0.8 \%$ at HRT of $5 \mathrm{~d}$ (Fig.5a), which significantly increased to $2.9 \%$ and $4.2 \%$ when the HRT decreased to 3 and $1.5 \mathrm{~d}$, respectively (Fig.5b and 5c). A species within genus Tepidanaerobacter, i.e. Tepidanaerobacter acetatoxydans, has previously been proved as a SAO bacterium (Westerholm et al., 2011) and Tepidanaerobacter syntrophicus was isolated from thermophilic $\left(55^{\circ} \mathrm{C}\right) \mathrm{AD}$ fed with either municipal solid waste or sewage sludge (Sekiguchi et al., 2006). SAOB genus Clostridium did not change significantly with the decrease in the HRT from $5 \mathrm{~d}$ to $1.5 \mathrm{~d}$ (Fig. 5a-c). The detected increase of SAOB indicated the presence of a SAO-HM pathway, which was promoted with the stepwise decrease of the HRT.

The archaeal community contained only hydrogenotrophic methanogens and strongly differed between the different HRTs (Fig. 5 a-c). When the HRT was decreased from $5 \mathrm{~d}$ to $3 \mathrm{~d}$ and then to $1.5 \mathrm{~d}$, the community richness and diversity decreased as depicted in former section (Table 4). GenusMethanoculleus dominated with $57 \%$ at an HRT of 5d (Fig.5a), and when the HRT was shortened to 3d, the genusMethanothermobacter became the most dominate archaea (93.8\%) (Fig.5b), which accompanied by an increase in its co-culture SAOB Tepidanaerobacter syntrophicus .Methanosarcia gradually decreased 1.7- and 2.4- fold along with 
shortening the HRT from 5 to 3 and 1.5 day, respectively. The doubling time of Methanothermobacterium sp. was around 1.8h (Huber et al., 1982), which was much shorter than the doubling time ofMethanoculleus sp. (12h) (Seely and Fahrney 1983). In addition, the doubling time of genus Methanosarcina andMethanosaeta were reported to be at least $36 \mathrm{~h}$ (Westerholm et al., 2011). During short HRT stages (5 to 1.5d), the faster growing hydrogenotrophic methanogens tend to dominate and revealed its functionally redundant properties which may syntrophically metabolize acetate with SAOB. In this study, the methane formation under the short HRT condition was therefore possibly through the SAO-HM pathway.

\section{Conclusions}

The current study revealed that thermophilic agro-food wastes could be operated at OLR of $10.2 \mathrm{~g}$ VS L-1 d-1 and HRT 5-8d with satisfactory stability and high methane yield. Process disturbances due to organic over loading and/or finite digestion time led to imbalance among interdepended reactions and thus digester acidification and subsequent process disturbances were experienced. The shaping in microbial profiles among stable and disturbed states suggested the occurrence of functional redundancy within AD microbiome. Conclusively, even though increasing OLR with shortening HRT is a feasible strategy for increasing process capacity at existing plants, the threshold of both parameters that guarantee the process stability should be carefully determined to avoid process disturbances. Since existence of disturbances is unavoidable in real systems, microbial community could be utilized as a pivotal bio-indicator to control AD process performance and stability.

\section{Acknowledgements}

The current study was supported partially by the Ministry of Science and Technology of China within the China-Italy Cooperation on FW Energy Utilization (SQ2013ZOA000017), and the Beijing Municipal Natural Science Foundation (No.6182017). The visits of David Bianchi and Camilla Negri in China Agricultural University were supported by the project (SQ2013ZOA000017). Dr. Ahmed Mahdy would like to thank for the financial support from State Administration of Foreign Experts Affairs P.R., China. (Project No. WQ20180011).

The summary of bacterial and archaeal communities for the first and second stages (class level) are shown in Support Information Table S1.

\section{References}

1. Algapani, D.E., Qiao, W., Su, M., Di, P.F., Wandera, S.M., Adani, F. \& Dong, R. (2016). Biohydrolysis and bio-hydrogen production from food waste by thermophilic and hyperthermophilic anaerobic process. Bioresour. Technol. 216,768-777. http://dx.doi.org/10.1016/j.biortech.2016.06.016.

2. APHA (2005). Standard Methods for the Examination of Water and Wastewater, American Public Health Association (APHA), Washington, DC, USA.

3. Bayrakdar, A., Sürmeli, R.Ö. \& Çalli, B. (2017). Dry anaerobic digestion of chicken manure coupled with membrane separation of ammonia. Bioresour. Technol. 244,816-823. https://doi.org/10.1016/j.biortech.2017.08.047.

4. Carballa, M., Regueiro, L., Lema, J.M. (2015). Microbial management of anaerobic digestion: exploiting the microbiome-functionality nexus. Curr. Opin. Biotech. 33,103111.https://dio.org/10.1016/j.copbio.2015.01.008

5. Chen, T., Jin, Y., Liu, F., Meng, X., Li, H. \& Nie, Y. (2012). Effect of hydrothermal treatment on the levels of selected indigenous microbes in food waste. J. Environ. Manage. 106,17-21. https://doi.org/10.1016/j.jenvman.2012.03.045.

6. Cho, K., Shin, S.G., Kim, W., Lee, J., Lee, C. \& Hwang, S. (2017). Microbial community shifts in a farmscale anaerobic digestion treating swine waste: Correlations between bacteria communities associated with hydrogenotrophic methanogens and environmental conditions. Sci. Total Environ. 601-602, 167176.http://dx.doi.org/10.1016/j.scitotenv.2017.05.188 
7. Conners, S.B., Mongodin, E.F., Johnson, M.R., Montero, C.I., Nelson, K.E. \& Kelly, R.M. (2006). Microbial biochemistry, physiology, and biotechnology of hyperthermophilic Thermotoga species. FEMS Microbiol, Rev. 30,872-905. https://doi.org/10.1111/j.1574-6976.2006.00039.x.

8. De Vrieze, J., Christiaens, M.E.R., Walraedt, D., Devooght, A., Ijaz, U.Z. \& Boon, N. (2017). Microbial community redundancy in anaerobic digestion drives process recovery after salinity exposure. Water Res. 111, 109-117. https://doi.org/10.1016/j.watres.2016.12.042

9. Dongyan, Y., Yunzhi, P., Hairong, Y., Shulin, C., Jingwei, M. \& Liang, Y. (2014). Enhancing biogas production from an anaerobically digested wheat straw through ammonia pretreatment. Chin. J. Chem. Eng. 22,576-582. https://doi.org/10.1016/S1004-9541(14)60075-6

10. Hania, W.B., Godbane, R., Postec, A., Hamdi, M., Ollivier, B. \& Fardeau, M.L. (2012). Defluviitoga tunisiensis gen. Nov., sp. Nov., a thermophilic bacterium isolated from a mesothermic and anaerobic whey digester. Int. J. Syst. Evol. Microbiol. 62,1377-1382. https://doi.org/10.1099/ijs.0.033720-0.

11. Hansen, K.H., Ahring, B.K. \& Raskin, L. (1999). Quantification of syntrophic fatty acid beta-oxidizing bacteria in a mesophilic biogas reactor by oligonucleotide probe hybridization. Appl, Environ. Microbiol. 65(11), 4767-4774.

12. Hobbs, S.R., Landis, A.E., Rittmann, B.E., Young, M.N. \& Parameswaran, P. (2019). Enhancing anaerobic digestion of food waste through biochemical methane potential assays at different substrate: inoculum ratios. Waste Manage. 71, 612-617. http://dx.doi.org/10.1016/j.wasman.2017.06.029.

13. Huber, H., Thomm, M., König, H., Thies, G. \& Stetter, K.O. (1982).Methanococcus thermolithotrophicus, a novel thermophilic lithotrophic methanogen. Arch. Microbiol.132,47-50. https://doi.org/10.1007/BF00690816.

14. Jang, H.M., Ha, J.H., Kim, M.S., Kim, J.O., Kim, Y.M. \& Park, J.M. (2016). Effect of increased load of high-strength food wastewater in thermophilic and mesophilic anaerobic codigestion of waste activated sludge on bacterial community structure. Water Res. 99, 140-148. https://doi.org/10.1016/j.watres.2016.04.051.

15. Jiang, M., Qiao, W., Ren, Z., Mahdy, A., Wandera, S.M., Li, Y. \& Dong, R. (2019). Influence of operation conditions on methane production from swine wastewater treated by a self-agitation anaerobic reacto. Int. Biodeter. Biodegr. 143,104710. https://doi.org/10.1016/j.ibiod.2019.05.027

16. Kim, J.K., Oh, B.R., Chun, Y.N. \& Kim, S.W. (2006). Effects of temperature and hydraulic retention time on anaerobic digestion of food waste. J. Biosci. Bioeng. 102, 328-332. https://doi.org/10.1263/jbb.102.328.

17. Li, D., Ran, Y., Chen, L., Cao, Q., Li, Z. \& Liu, X. (2018b). Instability diagnosis and syntrophic acetate oxidation during thermophilic digestion of vegetable waste. Water Res. 139, 263-271. https://doi.org/10.1016/j.watres.2018.04.019.

18. Li, W., Khalid, H., Zhu, Z., Zhang, R., Liu, G., Chen, C. \& Thorin, E. (2018a). Methane production through anaerobic digestion: participation and digestion characteristics of cellulose, hemicellulose and lignin. Appl. Energy 226, 1219-1228. https://doi.org/10.1016/j.apenergy.2018.05.055

19. Li, L., He, Q., Ma, Y., Wang, X. \& Peng, X. (2015). Dynamics of microbial community in a mesophilic anaerobic digester treating food waste: relationship between community structure and process stability. Bioresour. Technol. 189, 113-120.

20. Li, L., He, Q., Ma, Y., Wang, X. and Peng, X. (2016). A mesophilic anaerobic digester for treating food waste: process stability and microbial community analysis using pyrosequencing. Microb. Cell Fact. 15,65. https://doi.org/10.1186/s12934-016-0466-y

21. Li, L., Qin, Y., Kong, Z., Wu, J., Kubota, K. \& Li, Y-Y (2019). Characterization of microbial community and main functional groups of prokaryotes in thermophilic anaerobic cod-digestion of food waste and paper waste. Sci. Total Environ. 652, 709-717. https://doi.org/10.1016/j.scitotenv.2018.10.292

22. Liu, J.F., Mbadinga, S.M., Sun, X.B., Yang, G.C., Yang, S.Z., Gu, J.D. \& Mu, B,Z. (2016). Microbial communities responsible for fixation of $\mathrm{co} 2$ revealed by using mcra, cbbm, cbbl, fthfs, fefe-hydrogenase genes as molecular biomarkers in petroleum reservoirs of different temperatures. Int. Biodeter. Biodegr. 114,164-175. https://doi.org/10.1016/j.ibiod.2016.06.019.

23. Liu, P., Ji, J., Wu, Q., Ren, J., Wu, G., Yu, Z., Xiong, J., Tian, F., Zafar, Y. \& Li, X. (2018). Klebsiella 
pneumoniae sp lzu10 degrades oil in food waste and enhances methane production from co-digestion of food waste and straw. Int. Biodeter. Biodegr. 126,28-36. https://doi.org/10.1016/j.ibiod.2017.09.019.

24. Mahdy, A., Wandera, S.M., Bi, S., Song, Y., Qiao, W. \& Dong, R. (2019a). Response of the microbial community to the methanogenic performance of biologically hydrolyzed sewage sludge with variable hydraulic retention times. Bioresour. Technol. 288, 121581. https://doi.org/10.1016/j.biortech.2019.121581

25. Mahdy, A., Mendez, L., Ballesteros, M. \& Gonzalez-Fernandez, C. (2015). Protease pretreated Chlorella vulgaris biomass bioconversion to methane via semi-continuous anaerobic digestion. Fuel 158, 35-41.

26. Mahdy, A., Wandera, S.M., Qiao, W. \& Dong, R. (2019b). Biostimulation of sewage sludge solubilization and methanization by hyper-thermophilic pre-hydrolysis stage and the shifts of microbial structure profiles. Sci. Total Environ. https://doi.org/10.1016/j.scitotenv.2019.134373.

27. Marchaim, U. \& Krause, C. (1993). Propionic to acetic acid ratios in overloaded anaerobic digestion. Bioresour. Technol.43, 195-203. https://doi.org/10.1016/0960-8524(93)90031-6.

28. Maus, I., Koeck, D.E., Cibis, K.G., Hahnke, S., Kim, Y.S., Langer, T., Kreubel, J., Erhard, M., Bremges, A., Off, S., Stolze, Y., Jaenicke, S., Goesmann, A., Sczyrba, A., Scherer, P., König, H., Schwarz, W.H., Zverlov, V.V., Liebl, W., Pühler, A., Schlüter, A. \& Klocke, M. (2016). Unraveling the microbiome of a thermophilic biogas plant by metagenome and meta transcriptome analysis complemented by characterization of bacterial and archaeal isolates. Biotechnol. Biofuels 9, 171-198. https://doi.org/10.1186/s13068-016-0581-3.

29. Nag, R., Auer, A., Markey, B.K., Whyte, P., Nolan, S., O'flaherty, V., Russell, L., Declan, B., Fenton, O., Richards, K. \& Cummins, E. (2019). Anaerobic digestion of agricultural manure and biomassCritical indicators of risk and knowledge gaps. Sci. Total Environ. 690, 460-479.

30. Nayak, A. \& Bhushan, B. (2019). An overview of the recent trends on the waste valorization technologies for food wastes. J. Environ. Manage. 233, 352-370. https://doi.org/10.1016/j.jenvman.2018.12.041

31. Peng. X., Nges, I.A. \& Liu, J. (2016). Improving methane production form wheat straw by digestate liquor recirculation in continuous stirred tank processes. Renew. Energy 5,12-8. https://doi.org/10.1016/j.renene.2015.06.023

32. Ratanatamskul. C. \& Manpetch, P. (2016). Comparative assessment of prototype digester configuration for biogas recovery from anaerobic co-digestion of food waste and rain tree leaf as feedstock. Int. Biodeter. Biodegr. 13,367-374. http://dx.doi.org/10.1016/j.ibiod.2016.05.008.

33. Seely, R.J. \& Fahrney, D.E. (1983). A novel diphospho-p,p'-diester from Methanobacterium thermoautotrophicum . J. Biol. Chem. 258, 10835-10838. https://doi.org/10.1159/000177690

34. Sekiguchi, Y., Imachi, H., Susilorukmi, A., Muramatsu, M., Ohashi, A., Harada, H., Hanada, S. \& Kamagata, Y. (2006). Tepidanaerobacter syntrophicus gen. nov. sp. nov. an anaerobic, moderately thermophilic, syntrophic alcohol- and lactate-degrading bacterium isolated from thermophilic digested sludges. Int. J. Syst. Evol. Microbiol. 56,1621-1629. https://doi.org/10.1002/jps.20638.

35. Shi, X., Guo, X., Zuo, J., Wang, Y. \& Zhang, M. (2018). A comparative study of thermophilic and mesophilic anaerobic co-digestion of food waste and wheat straw: process stability and microbial community structure shifts. Waste Manage. 75,261-269. http://doi.org/10.1016/j.wasman.2018.02.004.

36. Sluiter, A., Hames, B., Ruiz, R., Scarlata, C., Sluiter, J. \& Templeton, D. (2005). Determination of Ash in biomass. Standard Biomass Analytical Procedures. National Laboratory of the U.S. Determent of Energy, Office of Energy Efficiency \& Renewable Energy, United States.

37. Sun. L., Pope, P.B., Eijsink, V.G.H. \& Schnurer, A. (2015). Characterization of microbial community structure during continuous anaerobic digestion of straw and cow manure. Microbial Biotechnol. 8, 815-827. https://doi.org/10.1111/1751-7915.12298.

38. Tachaapaikoon, C., Kosugi, A., Pason, P., Waeonukul, R., Ratanakhanokchai, K., Kyu, K.L., Arai, T., Murata, Y. \& Mori, Y. (2012). Isolation and characterization of a new cellulosome-producing Clostridium thermocellum strain. Biodegradation 23(1), 57-68. https://doi.org/10.1007/s10532-011-9486-9.

39. Tian, H., Fotidis, I.A., Mancini, E., Treu, L., Mahdy, A., Ballesteros, M., González-Fernández, C. \& Angelidaki, I. (2018). Acclimation to extremely high ammonia levels in continuous biomethana- 
tion process and the associated microbial community dynamics. Bioresour. Technol. 247, 616-623. http://dx.doi.org/10.1016/j.biortech.2017.09.148

40. Wagner, A.O., Reitschuler, C. \& Illmer, P. (2014). Effect of different acetate:propionate ratios on the methanogenic community during thermophilic anaerobic digestion in batch experiments. Biochem. Eng. J. 90, 154-161. https://doi.org/10.1016/j.bej.2014.05.014.

41. Westerholm, M., Moestedt, J. \& Schnürer, A. (2016). Biogas production through syntrophic acetate oxidation and deliberate operating strategies for improved digester performance. Appl. Energy 179, 124-135. https://doi.org/10.1016/j.apenergy.2016.06.061.

42. Westerholm, M., Roos, S. \& Schnürer, A. (2011). Tepidanaerobacter acetatoxydans sp. nov. an anaerobic, syntrophic acetate-oxidizing bacterium isolated from two ammonium-enriched mesophilic methanogenic processes. Syst. Appl. Microbiol. 34, 260-266. https://doi.org/10.1016/j.syapm.2010.11.018.

43. Yin, D.M., Westerholm, M., Qiao, W., Bi, S.J., Wandera, S.M., Fan, R., Jiang, M. \& Dong, R. (2018). An explanation of the methanogenic pathway for methane production in anaerobic digestion of nitrogen-rich materials under mesophilic and thermophilic conditions. Bioresour. Technol. 264, 42-50. https://doi.org/10.1016/j.biortech.2018.05.062.

44. Zamanzadeh, M., Hagen, L.H., Svensson, K., Linjordet, R. \& Horn, S.J. (2017). Biogas production from food waste via co-digestion and digestion- effects on performance and microbial ecology. Sci. Rep. 7, 17664-17676. https://doi.org/10.1038/s41598-017-15784-w.

45. Zhang, Q., Wang M., Ma, X., Gao, Q., Wang, T., Shi, X., Zhou, J., Zuo, J. \& Yang, Y. (2019). High variations of methanogenic microorganisms drive full-scale anaerobic digestion process. Environ. Int. 126, 543-551. https://doi.org/10.1016/j.envint.2019.03.005

Table 1. Characteristics of substrates and inoculum

\begin{tabular}{llllllllll}
\hline Parameters & Units & Food Waste & Food Waste & Food Waste & Straw & Straw & Straw & Inoculum & Inoculum \\
\hline & & Average & SD $( \pm)$ & $\mathrm{n}$ & Average & SD $( \pm)$ & $\mathrm{n}$ & Average & SD $( \pm)$ \\
TS & $\%$ & 15.4 & 1.4 & 14 & 95.5 & 0.12 & 2 & 8.4 & 0.1 \\
VS & $\%$ & 13.9 & 1.2 & 14 & 84.7 & 0.1 & 2 & 5.3 & 0.1 \\
VS/TS & $\%$ & 90.3 & 0.7 & 14 & 88.7 & $/$ & $/$ & 63 & 0.2 \\
TCOD & g kg-1 & 185 & 42.5 & 14 & $1.2^{*}$ & 0.1 & 2 & 21 & 0.4 \\
SCOD & gL-1 & 100 & 15.2 & 14 & $/$ & $/$ & 2 & 17.9 & 0.5 \\
Carbohydrates & TS\% & 24 & 9.1 & 14 & $/$ & $/$ & $/$ & $/$ & $/$ \\
Protein & TS\% & 12 & 7.0 & 14 & $/$ & $/$ & $/$ & $/$ & $/$ \\
Fat & TS\% & 21.5 & 5.8 & 14 & $/$ & $/$ & $/$ & $/$ & $/$ \\
C & TS\% & 51.1 & 1.3 & 2 & 58.2 & 0.1 & 2 & $/$ & $/$ \\
N & TS\% & 3.6 & 0.4 & 2 & 1.1 & 0 & 2 & $/$ & $/$ \\
O & TS\% & 37.9 & 0.7 & 2 & 34.4 & 0.1 & 2 & $/$ & $/$ \\
H & TS\% & 5.1 & 0.1 & 2 & 4.8 & 0.1 & 2 & $/$ & $/$ \\
S & TS\% & 2.4 & 0.9 & 2 & 0.9 & 0.1 & 2 & $/$ & $/$ \\
C/N & $/$ & 14.2 & 1.1 & 2 & 52.9 & 0.3 & 2 & $/$ & $/$ \\
\hline
\end{tabular}

Notes: TS: total solids; VS: volatile solids; VFAs: volatile fatty acids; TCOD: total chemical oxygen demand; SCOD: soluble chemical oxygen demand; SD: standard deviation; n means testing frequency; '/': data not available. *: g COD g TS-1.

Table 2 Summary of long term CSTR process performances under stable and disturbed states

\begin{tabular}{lllllllll}
\hline Duration & Days $^{*}$ & $1-47$ & $48-110$ & $111-160$ & $161-202$ & $203-218$ & $219-230$ & $231-252$ \\
\hline Feeding VS & g L-1 & $79.1 \pm 4.5$ & $80.8 \pm 5.4$ & $79.4 \pm 4.8$ & $81.2 \pm 4.4$ & $85.1 \pm 5.4$ & Stop feeding & $40.1 \pm 0.2$
\end{tabular}




\begin{tabular}{lllllllll}
\hline Duration & Days* & $1-47$ & $48-110$ & $111-160$ & $161-202$ & $203-218$ & $219-230$ & $231-252$ \\
\hline OLR & g VS L-1 d-1 & $2.6 \pm 0.2$ & $5.4 \pm 0.4$ & $7.9 \pm 0.5$ & $10.2 \pm 0.6$ & $17.1 \pm 1.1$ & $/$ & $8.1 \pm 0.1$ \\
HRT & Days & 30 & 15 & 10 & 8 & 5 & $/$ & 5 \\
pH & $/$ & $7.6 \pm 0.1$ & $7.5 \pm 0.1$ & $7.4 \pm 0.3$ & $7.4 \pm 0.2$ & $7.2 \pm 0.3$ & $/$ & $7.2 \pm 0.1$ \\
Biogas yield & L L-1 d-1 & $0.9 \pm 0.2$ & $3.0 \pm 0.7$ & $4.6 \pm 0.5$ & $5.7 \pm 0.7$ & $9.1-6.1$ & $/$ & $4.4 \pm 0.3$ \\
CH4 & $\%$ & $63 \pm 3$ & $61 \pm 4$ & $61 \pm 3$ & $61 \pm 3$ & $61 \pm 9$ & $/$ & $65 \pm 4$ \\
CO2 & $\%$ & $29 \pm 2$ & $32 \pm 4$ & $33 \pm 3$ & $34 \pm 3$ & $31 \pm 7$ & $/$ & $35 \pm 4$ \\
Specific methane yield & mL g VSin-1 & $284 \pm 74$ & $348 \pm 59$ & $393 \pm 25$ & $385 \pm 43$ & $306-205$ & $/$ & $354 \pm 27$ \\
NH4+-N & mg L-1 & $835 \pm 103$ & $732 \pm 12$ & $644 \pm 92$ & $667 \pm 92$ & $550 \pm 13$ & $/$ & $0.8 \pm 0.2$ \\
Bicarbonate alkalinity & g CaCO3 L-1 & $3.5 \pm 0.4$ & $4.4 \pm 0.3$ & $4.1 \pm 0.4$ & $4.1 \pm 0.3$ & $3.7-2.1$ & $/$ & $2.8 \pm 0.4$ \\
Acetate & mg L-1 & $83 \pm 42$ & $212 \pm 41$ & $204 \pm 31$ & $338 \pm 185$ & $242-1411$ & $/$ & $333 \pm 197$ \\
Propionate & mg L-1 & $22 \pm 14$ & $21 \pm 12$ & $8 \pm 4$ & $46 \pm 28$ & $17-2213$ & $/$ & $558 \pm 296$ \\
Butyrate & mg L-1 & $20 \pm 10$ & $7 \pm 3$ & $14 \pm 5$ & $10 \pm 3$ & $13-507$ & $/$ & $266 \pm 248$ \\
Total VFAs & mg L-1 & $124 \pm 100$ & $226 \pm 52$ & $214 \pm 34$ & $398 \pm 28$ & $362-4730$ & $/$ & $916 \pm 463$ \\
\hline
\end{tabular}

Notes: HRT: hydraulic retention time; TS: total solid; OLR: organic loading rate; Total VFAs: volatile organic acids, sum of acetate, propionate, iso-butyrate, butyrate, iso-valerate, valeric and caproate; '/': data not available. All data is shown in average $\pm \mathrm{SD}$ (standard deviation); '-' means the performance range, not stable.

*: First stage: 1-218 days; Recovery stage: 219-230 days; Second stage: 231-252 days

Table 3 Percentage of potential SAOB and HM partners at genus level

\begin{tabular}{lllllll}
\hline & OLR (g VS L-1 d-1) & 10.2 & 17.1 & 8.1 & 7.4 & 7.7 \\
\hline \multirow{5}{*}{ Possible SAOB } & HRT (days) & 8 & 5 & 5 & 3 & 1.5 \\
& Tepidanaerobacter & $0.02 \%$ & $0.4 \%$ & $1 \%$ & $3 \%$ & $4 \%$ \\
& Clostridium & $2 \%$ & $11 \%$ & $5 \%$ & $4 \%$ & $7 \%$ \\
& Syntrophaceticus & $/$ & $0.1 \%$ & $/$ & $/$ & $/$ \\
& Total & $3 \%$ & $12 \%$ & $6 \%$ & $7 \%$ & $11 \%$ \\
& Methanothermobacter & $1 \%$ & $1 \%$ & $24 \%$ & $75 \%$ & $84 \%$ \\
& Methanoculleus & $87 \%$ & $53 \%$ & $56 \%$ & $0.1 \%$ & $1 \%$ \\
& Methanomassiliicoccus & $3 \%$ & $7 \%$ & $4 \%$ & $0.2 \%$ & $1 \%$ \\
& Total & $91 \%$ & $61 \%$ & $84 \%$ & $75 \%$ & $86 \%$ \\
\hline
\end{tabular}

Notes: '/' was not detected. SAOB: syntrophic acetate oxidation bacterial; HM: hydrogenotrophic methanogenic.

Table 4 Microbial richness and diversity indices of bacterial (genus level) and archaeal (species level) under HRT 5-1.5d

\begin{tabular}{lllllllll}
\hline HRT $(\mathrm{d})$ & Bacterial & Bacterial & Bacterial & Bacterial & Archaeal & Archaeal & Archaeal & Archaeal \\
\hline & Chao1 & Shannon & Simpson & Coverage & Chao1 & Shannon & Simpson & Coverage \\
5 & 2978 & 6.76 & 0.97 & 0.93 & 28 & 1.17 & 0.97 & 0.99 \\
3 & 2213 & 6.66 & 0.96 & 0.93 & 21.5 & 0.76 & 0.88 & 0.99 \\
1.5 & 1989 & 6.32 & 0.95 & 0.90 & 20 & 0.65 & 0.72 & 0.99 \\
\hline
\end{tabular}

Notes: all indices were calculated based on OTU level 


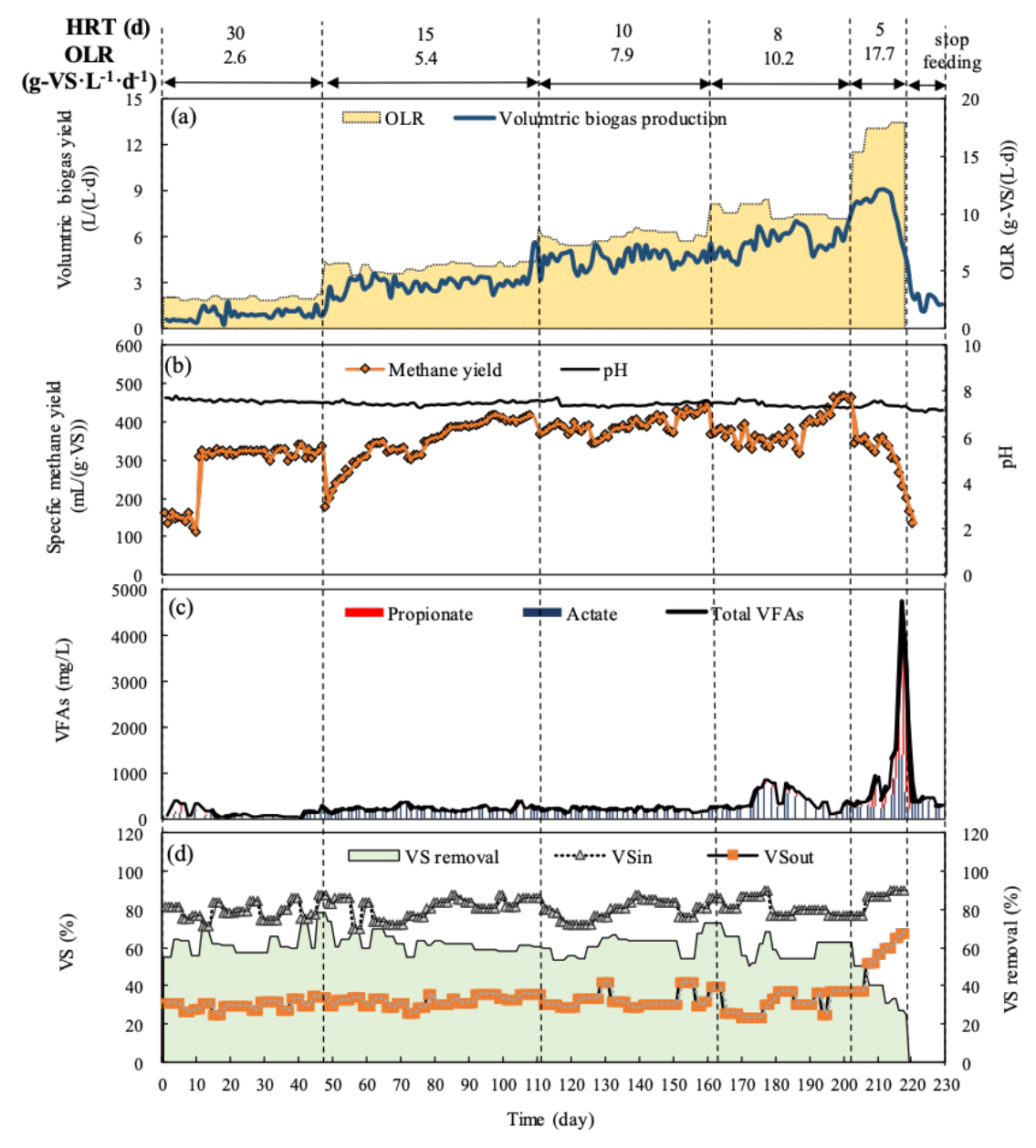

Fig. 1 CSTR performance in long-term operation under stable and disturbed states targeting OLR: (a) volumetric methane production, (b) methane yield and $\mathrm{pH}$, (c) total VFAs, acetate and propionate and (d) VS in, out and removal 


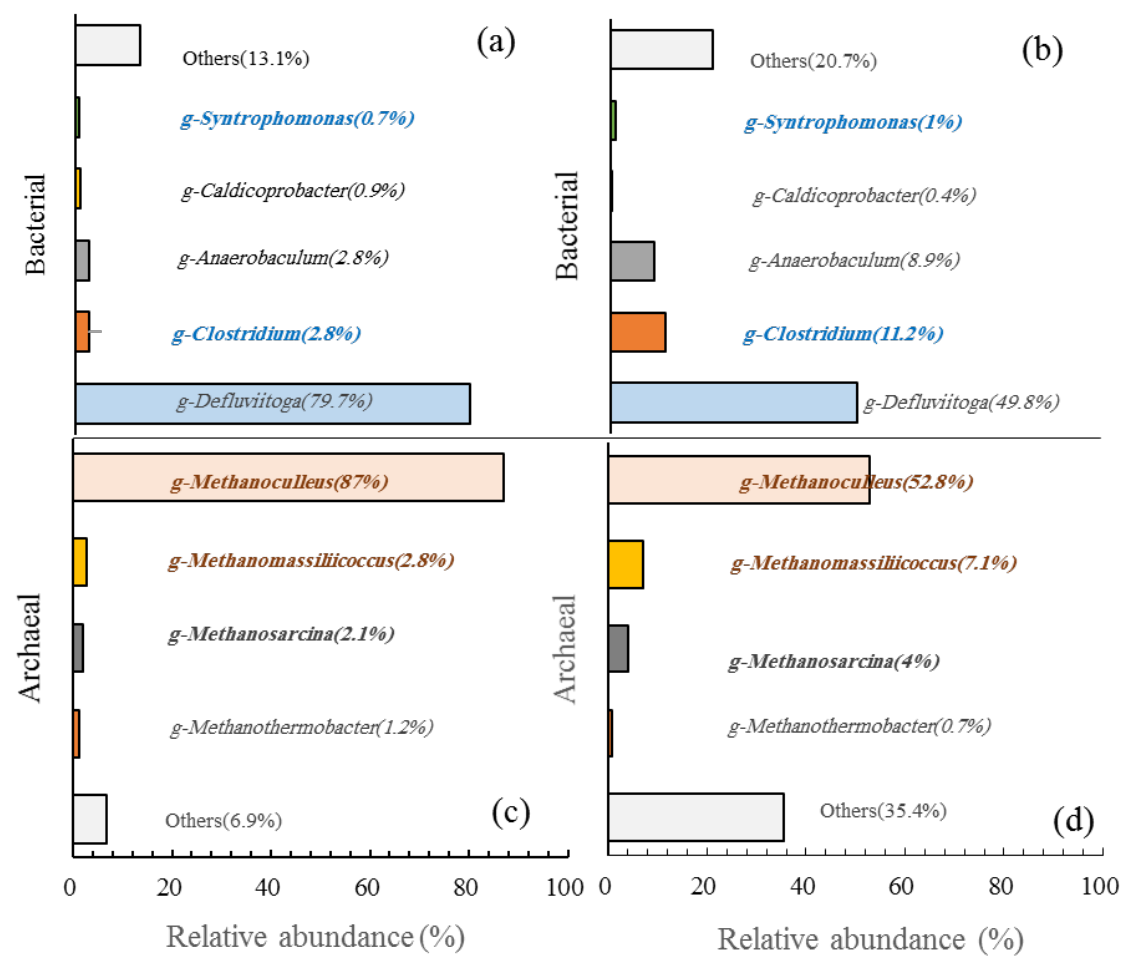

Fig. 2 Relative abundance of bacteria and archaea at genus taxonomic level under well-performed (a and c) and disturbed (b and d) states. 


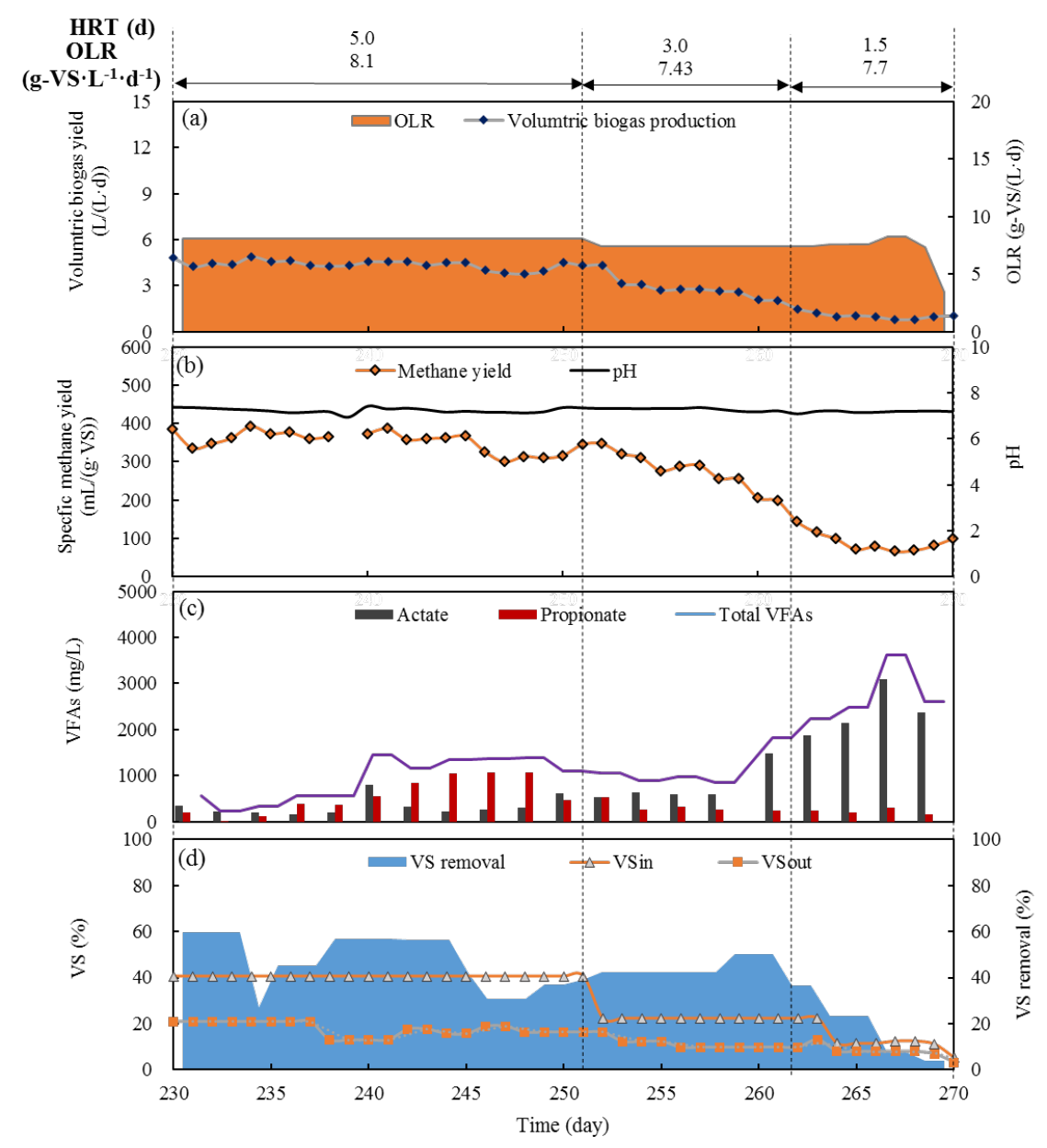

Fig 3. CSTR performance under stable and disturbed states targeting HRT: (a) volumetric methane production, (b) methane yield and $\mathrm{pH}$, (c) total VFAs, acetate and propionate and (d) VS in, out and removal

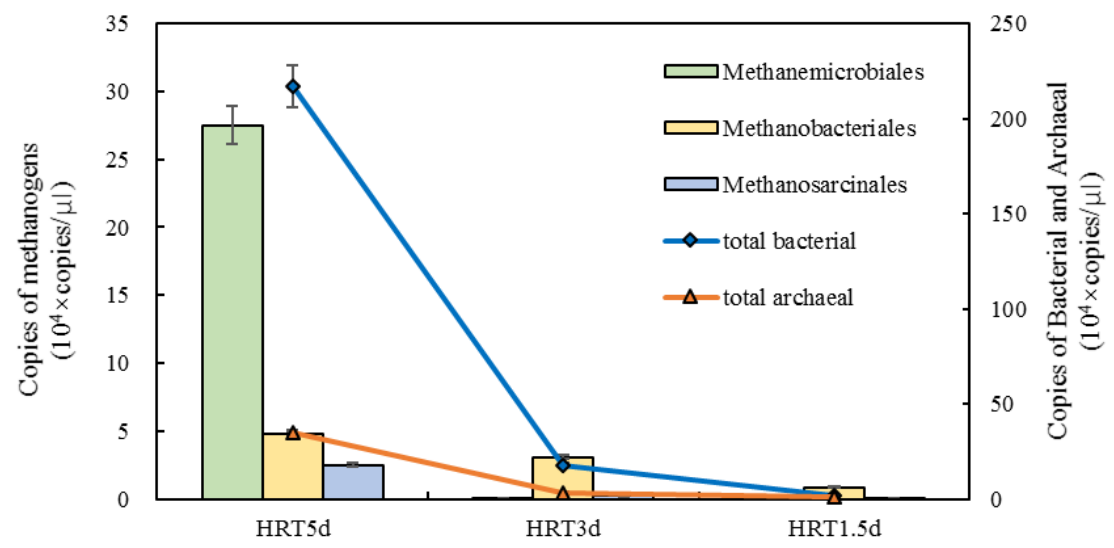

Fig. 4 Wash out of microorganisms with reducing HRTs. 


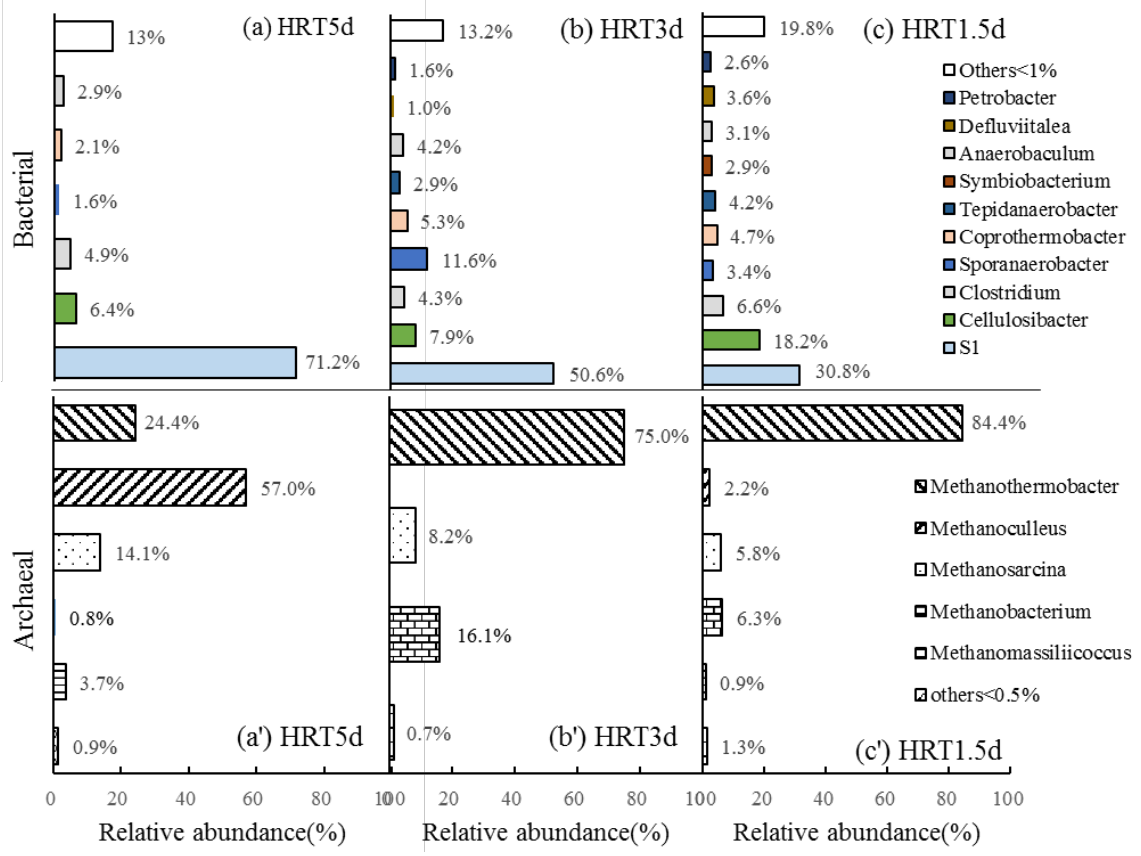

Fig. 5 Relative abundance of bacteria (a, b and c) and archaea (a', b' and c') at genus taxonomic level under stable and disturbed states targeting HRT.

\section{Hosted file}

Graphical abstract.docx available at https://authorea.com/users/287467/articles/412222anaerobic-digestion-concert-of-agro-food-wastes-and-the-correlated-microbial-populationdynamics-under-suboptimal-well-performed-and-disturbed-states 